\title{
Is the quantity of circulatory cell-free DNA in human plasma and serum samples associated with gender, age and frequency of blood donations?
}

\author{
Xiao Yan Zhong • Sinuhe Hahn • Vivian Kiefer • \\ Wolfgang Holzgreve
}

Received: 1 March 2006 / Accepted: 20 July 2006 / Published online: 6 October 2006

(C) Springer-Verlag 2006

\begin{abstract}
Circulatory cell-free DNA (cf-DNA) is increased in a variety of clinical pathologic conditions; therefore, these markers could be widely used as markers for detecting and monitoring several disorders. To better understand the biology of this molecule, we analysed the relationship between the level of circulatory cf-DNA and physiological parameters such as gender, age and frequency of blood donations. Paired plasma and serum samples were obtained from 87 blood donors and 50 healthy adults who had never donated blood. Cf-DNA was extracted from plasma and serum samples using the MagNA Pure LC Instrument. Quantity determination of circulatory cf-DNA was performed by TaqMan real-time PCR for the ubiquitous GAPDH gene. Our data showed that the concentration of cf-DNA in serum was about eightfold higher than that in plasma. Regarding the level of these circulatory species, no significant differences were observed between the agematched men and women and gender-matched, differentage cohorts, except in women who were older than 60 years of age. Frequent blood donations did not increase the circulatory species. Circulatory cf-DNA in plasma and serum samples is not correlated with human gender and human age except in women who are older than 60 years of age. Frequent blood donation did not affect the quantity of circulatory cf-DNA. The explanation for the latter most likely is the short half-life time of free fetal DNA in maternal circulation.
\end{abstract}

X. Y. Zhong $(\bowtie) \cdot S$. Hahn $\cdot$ V. Kiefer $\cdot$ W. Holzgreve

Laboratory for Prenatal Medicine and Experimental Oncology,

Department of Obstetrics and Gynecology,

University of Basel,

Spitalstrasee 21,

CH 4031 Basel, Switzerland

e-mail: xzhong@uhbs.ch
Keywords Circulatory cf-DNA $\cdot$ Plasma $\cdot$ Serum · Human gender $\cdot$ Human age $\cdot$ Blood donation

\section{Introduction}

High concentrations of cell-free DNA (cf-DNA) in plasma and serum samples have been widely described in a variety of clinical pathologic conditions, such as malignancies, trauma, infections, pregnancy-associated disorders and autoimmune diseases [1-5]. Therefore, circulatory cf-DNA as a biological marker has been used recently more for the investigation of the biological nature of disease and for clinical diagnostic applications, especially in two major areas: cancer management and prenatal diagnosis [6-10]. In cancer patients, the levels of circulatory DNA correlated with tumour metastasis, tumour response to therapy and tumour recurrence. Tumour-derived circulatory nucleic acids in the plasma or serum of cancer patients have been introduced as a non-invasive tool for detection and surveillance of several cancers $[1,2,6,7]$. Cell-free fetal DNA in the maternal circulation has been used for detecting and monitoring certain fetal diseases and pathological pregnancies, such as fetal-maternal haemorrhage, preeclampsia and preterm labour and fetal chromosomal aberrations [11-14]. Recently, it was shown that DNA fragments released from programmed cell death or acute cellular injury are the main sources for circulatory cf-DNA in a variety of clinical pathologic conditions [15-18]. However, the cellular or tissue origin of circulatory cf-DNA existing in normal healthy individuals is unclear. We detected cf-DNA in plasma and serum samples of healthy individuals and healthy blood donors from the Blood Bank, University of Basel, and analysed the correlation between levels of circulatory cf-DNA and age, gender or 
frequency of blood donations to determine whether any quantitative changes of circulatory cf-DNA are associated with physiological parameters.

\section{Materials and methods}

Sample collection

Paired plasma and serum samples were obtained from 50 healthy adults by clinical detection at University Women's Hospital and Felix Platter Hospital of Basel and from 87 healthy blood donors. The study was approved by the institutional review board of the University of Basel. Informed consent was obtained from the individuals in this study.

Processing of blood samples

The $10 \mathrm{ml}$ of peripheral blood samples for coagulant serum and $10 \mathrm{ml}$ of peripheral blood samples for EDTA plasma were taken from healthy individuals and blood donors. The blood samples were processed immediately by centrifugation at $1,600 \mathrm{~g}$ for $10 \mathrm{~min}$. The plasma and serum layers were transferred to new Eppendorf tubes and centrifuged again at maximum speed $(16,000 \mathrm{~g})$ for $10 \mathrm{~min}$.
DNA extraction

Circulatory cf-DNA was extracted from each $400-\mu$ l plasma and serum sample using the MagNA Pure LC DNA Isolation Kit-Large Volume (Roche Applied Science, Mannheim, Germany) and the MagNA Pure LC Instrument according to the manufacturer's protocol. The DNA preparations were eluted in $100 \mu$ l elution buffer according to MagNA Pure LC software.

Quantitative analysis of cf-DNA in plasma and serum samples

Five microliters of DNA was used as template for the TaqMan real-time PCR analysis. The TaqMan PCR conditions were standardised in our lab and have been described previously in our various publications [9, 10, 12-14]. The circulatory cf-DNA equivalents were calculated according to very reproducible standard dilution curves using a known concentration of human genomic DNA. The concentrations of circulatory cf-DNA were expressed as genomic equivalents per milliliter plasma or serum.

Statistical analysis

Data were analysed with SPSS software (Statistical Software Package for Windows). Mann-Whitney U test and Kruskal-Wallis $\mathrm{H}$ were used to compare the levels of
Fig. 1 Correlation of circulatory cf-DNA levels with age and gender. Box plot indicating cfDNA levels [y axis, genomic equivalents $(\mathrm{GE}) / \mathrm{ml}]$ in the study groups categorised by gender and age ( $x$ axis, $f$ female, $m$ male, $p$ plasma, $s$ serum, 20 age 20-40, 41 age 41-61, 61 age $\geq 61$ ). The medians are indicated by a line inside each box, the 75 th and 25 th percentiles by the box limits; the upper and lower error bars represent the 10th and 90th percentiles, respectively. The plasma cf-DNA in the study group of $\mathrm{f} 61 \mathrm{p}$ $(1978 \mathrm{GE} / \mathrm{ml}, N=8)$ is higher than that in the study groups of f20p $(943 \mathrm{GE} / \mathrm{ml}, N=26$, $p=0.008)$ and $\mathrm{f} 41 \mathrm{p}(1126 \mathrm{GE} / \mathrm{ml}$, $N=24, p=0.018$ )

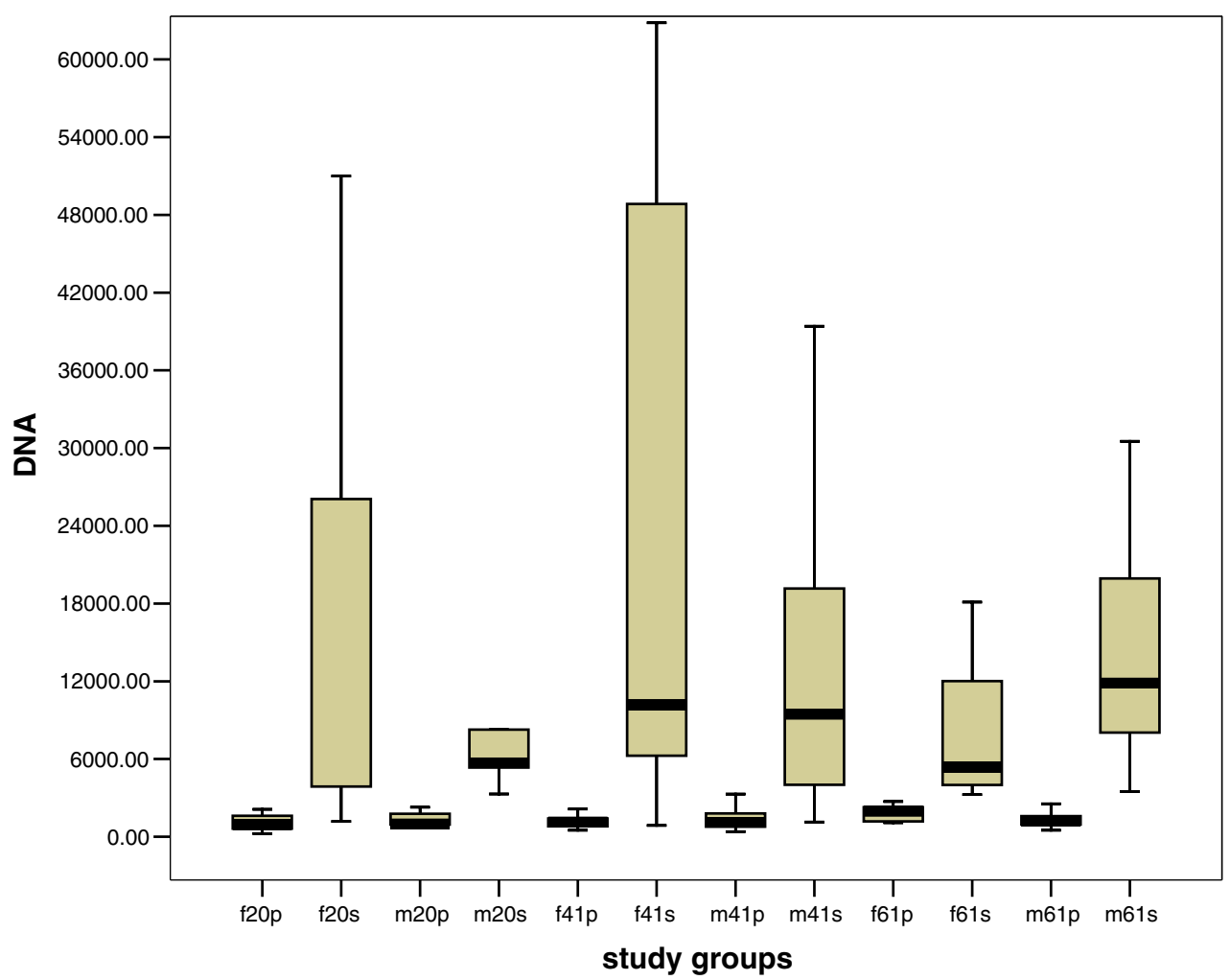


circulatory cf-DNA in different groups categorised by gender, age and frequency of blood donations.

\section{Results}

Levels of circulatory cf-DNA in plasma and serum samples

Because the plasma and serum samples were paired, collected and prepared simultaneously, a mean concentration of $1,121.5$ copies $/ \mathrm{ml}$ was detected in the plasma samples, whereas the circulatory cf-DNA had a mean of 9,285 copies/ml in the paired serum samples. This was about eightfold higher than the mean concentration of the circulatory cf-DNA in plasma samples. The difference was statistically significant $(p<0.001)$.

Levels of circulatory cf-DNA in male/female plasma and serum

We compared the levels of circulatory cf-DNA in 54 agematched female and male plasma and serum samples. The mean concentrations of circulatory cf-DNA in female plasma and serum samples were 1,136 and 8,854.5 copies/ml, respectively, and in male plasma and serum samples, they were $1,117.5$ and 9,259 copies/ml, respectively. The levels of circulatory cf-DNA in serum samples in both the female and male groups were 7.56 and 8.04 times higher than in the plasma samples. Regarding the level of circulatory cf-DNA in plasma and serum samples, no significant difference was found between women and men.

The levels of circulatory cf-DNA and age

No significant correlation was observed between the age of the individuals and the concentration of circulatory cf-DNA in plasma and serum samples using the Pearson test. The cases in this study were grouped into three different age cohorts, namely the groups of 20-40 years of age, 41-60 years of age and older than 60 years of age. The levels of circulatory cf-DNA in the three different age cohorts were determined (977, 1,119 and 1,321 copies/ml plasma, respectively, and 8,438, 9,839 and 9,239 copies/ml serum, respectively). The mean concentration of circulatory cfDNA in the plasma samples from the age cohort of women and men older than 60 years was higher than the other two age cohorts of women and men younger than 60 years of age $(p<0.05)$. Further analysis showed that the increase was only found in the female group from the age cohort of older than 60 years of age $(p<0.05)$ compared to the two younger female groups, but not in the male group (Fig. 1). No difference was found between women and men in the same age cohort of older than 60 years of age. In contrast to the plasma samples, the level of circulatory cf-DNA in serum samples was not age-associated.
Fig. 2 The levels of circulatory cf-DNA and frequency of donations. Box plot indicating cfDNA levels (y axis, genomic equivalents $/ \mathrm{ml}$ ) in the study groups categorised by frequency of blood donations ( $x$ axis, $0-80$ frequencies of blood donations, $p$ plasma, $s$ serum). The level of serum cf-DNA in the study group 11-50 $(N=27)$ was significantly lower than those in the study groups $0(N=25)$ and $11(N=27)$ (Mann-Whitney test, $p=0.007,0.016$ )

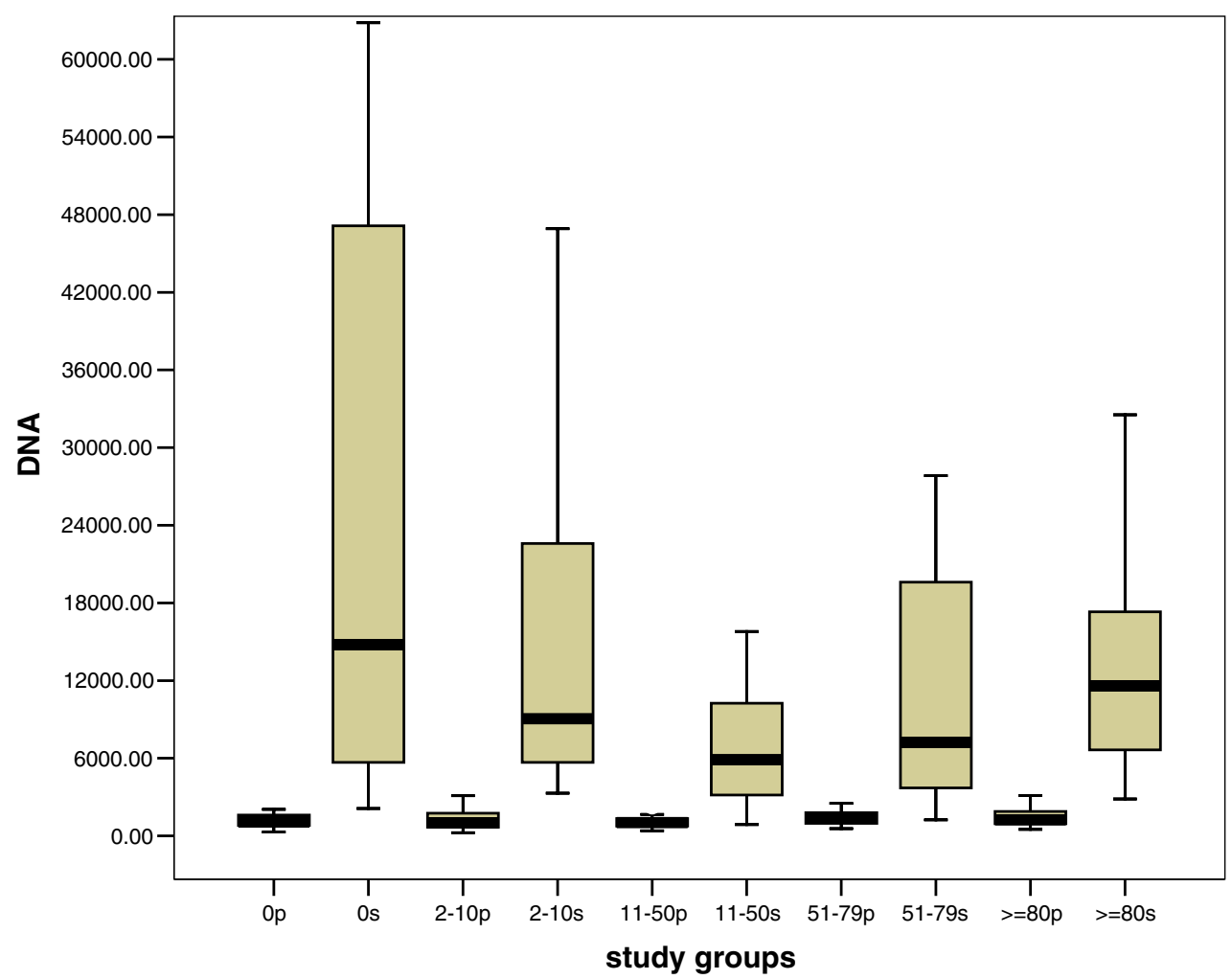


The levels of circulatory cf-DNA and frequency of blood donations

Eighty-seven healthy individuals donated blood as part of this study at the University Blood Bank. The frequency of their blood donations ranged from 2 to 128 times (maximum of four times/year and $400 \mathrm{ml} / \mathrm{time}$ ). We evaluated whether the frequency of blood donations might influence the release of cellular DNA into plasma and serum fractions. The comparison between the concentration of circulatory cf-DNA and the frequency of blood donations is summarised in Fig. 2. The concentration of circulatory cf-DNA in the serum samples of the blood donors who have donated blood between 11 and 50 times was statistically significantly lower than in the individuals who had never previously donated blood or had donated blood fewer than 11 times (Mann-Whitney test, $p<0.05$ ). No significant differences were observed in the other groups.

\section{Discussion}

In our work, circulatory cf-DNA was determined by realtime PCR with a mean concentration of $1,121.5$ copy numbers $/ \mathrm{ml}$ in plasma samples and 9,285 copy numbers $/ \mathrm{ml}$ in serum samples. Similar results that serum samples have a higher concentration of cf-DNA have been reported earlier [19]. The release of DNA during blood clotting, causing higher levels of DNA molecules in serum samples, has been confirmed by several studies [18, 19]. Therefore, this phenomenon might provide an opportunity in the future to examine the fragility of haematopoitic cells.

Regarding the origin of circulatory cf-DNA, Liu et al. had investigated the contribution of haematopoietic and non-haematopoietic cells to these molecules using a gendermismatched bone marrow transplantation model (female patients receiving bone marrow from male donors and male patients receiving from female donors) [18]. The study confirmed that haematopoietic cells are the main sources of plasma cf-DNA. However, the distributing of lineages of haematopoietic cells contributing to the release of cf-DNA in the circulation remains unclear. Because total RBC counts are known to be greater in men, we examined whether the concentration of circulatory cf-DNA might also be gender-related. In our study, no significant differences concerning circulatory levels of cf-DNA between the female and male groups were found, implying that gender-associated differences of total RBC counts and other physiological conditions did not influence the release of DNA in circulation.

Age-related differences regarding physiological status and pathological conditions are well-known. To determine whether the age might be associated with the level of circulating cf-DNA, we compared the age of the individuals with the mean concentration of cf-DNA in plasma and serum samples. No significant correlation existed between age and copy number of cf-DNA (Pearson test). The cases in this study were grouped into three different age cohorts of 20-40 years, $41-60$ years and older than 60 years. Only the female individuals in the oldest group (menopause) had significantly higher circulating cf-DNA in their plasma than the two younger groups. No significant difference was found between the men and the women in the same group of over 60 years of age. The slight increased plasma cfDNA in the women of over 60 may be a statistical artefact because of the limited sample sets.

In our study, individuals who donated blood frequently compared to the individuals who had never previously donated blood, namely, the donors who donated blood between 11 and 50 times compared to those who donated fewer than 11 times, had significantly lower circulatory levels of cf-DNA in serum samples, but not in plasma samples. As we mentioned above, if the release of the cfDNA reflects the fragility of haematopoietic cells, our results could suggest that frequent blood donations may decrease the fragility of haematopoietic cells and reduce the release of DNA from blood clotting in serum samples. Usually, the donors are allowed to repeat giving blood once every 56 days (five times per year). In our study, one donor donated blood 128 times. Our data show that highly frequent blood donations ( $>80$ times) did not cause any differences in circulating cf-DNA in plasma and serum compared to the other healthy individuals.

In conclusion, circulatory cf-DNA in plasma and serum samples is not associated with gender and age. Overall, frequent blood donations did not appear to affect the levels of circulating cf-DNA. This most likely is due to the short half-life time of free fetal DNA in maternal circulation. Any association between the development of blood donationlinked complications and the levels of circulating cf-DNA can be further investigated.

Acknowledgments We thank Dr. Dorothy Huang for her helpful comments and for reviewing the English. We thank Dr. Paul Hasler and the University Blood Bank of Basel for providing samples.

\section{References}

1. Boddy JL, Gal S, Malone PR, Harris AL, Wainscoat JS (2005) Prospective study of quantitation of plasma DNA levels in the diagnosis of malignant versus benign prostate disease. Clin Cancer Res 11(4):1394-1399

2. Gautschi O, Bigosch C, Huegli B, Jermann M, Marx A, Chasse E, Ratschiller D, Weder W, Joerger M, Betticher DC, Stahel RA, Ziegler A (2004) Circulating deoxyribonucleic acid as prognostic 
marker in non-small-cell lung cancer patients undergoing chemotherapy. J Clin Oncol 22(20):4157-4164

3. Lam NY, Rainer TH, Chan LY, Joynt GM, Lo YM (2003) Time course of early and late changes in plasma DNA in trauma patients. Clin Chem 49(8):1286-1291

4. Lee TH, Montalvo L, Chrebtow V, Busch MP (2001) Quantitation of genomic DNA in plasma and serum samples: higher concentrations of genomic DNA found in serum than in plasma. Transfusion 41(2):276-282

5. Leung TN, Zhang J, Lau TK, Chan LY, Lo YM (2001) Increased maternal plasma fetal DNA concentrations in women who eventually develop preeclampsia. Clin Chem 47(1):137139

6. Chun FK, Muller I, Lange I, Friedrich MG, Erbersdobler A, Karakiewicz PI, Graefen M, Pantel K, Huland H, Schwarzenbach H (2006) Circulating tumour-associated plasma DNA represents an independent and informative predictor of prostate cancer. BJU Int 98(3):544-548

7. Goebel G, Zitt M, Muller HM (2005) Circulating nucleic acids in plasma or serum (CNAPS) as prognostic and predictive markers in patients with solid neoplasias. Dis Markers 21 (3): 105-120

8. Chiu TW, Young R, Chan LY, Burd A, Lo DY (2006) Plasma cf-DNA as an indicator of severity of injury in burn patients. Clin Chem Lab Med 44(1):13-17

9. Zhong XY, Holzgreve W, Hahn S (2002) The levels of circulatory cell-free fetal DNA in maternal plasma are elevated prior to the onset of preeclampsia. Hypertens Pregnancy 21 (1):77-183

10. Zhong XY, Holzgreve W, Hahn S (2001) Circulatory fetal and maternal DNA in pregnancies at risk and those affected by preeclampsia. Ann N Y Acad Sci 945:138-140

11. Lo YM, Tein MS, Lau TK, Haines CJ, Leung TN, Poon PM, Wainscoat JS, Johnson PJ, Chang AM, Hjelm NM (1998)
Quantitative analysis of fetal DNA in maternal plasma and serum: implications for noninvasive prenatal diagnosis. Am J Hum Genet 62(4):768-775

12. Zhong XY, Holzgreve W, Hahn S (2001) Risk free simultaneous prenatal identification of fetal Rhesus D status and gender by multiplex real-time PCR using cell-free fetal DNA in maternal plasma. Swiss Med Wkly 131(5-6):70-74

13. Zhong XY, Laivuori H, Livingston JC, Ylikorkala O, Sibai BM, Holzgreve W, Hahn S (2001) Elevation of both maternal and fetal extracellular circulating deoxyribonucleic acid concentrations in the plasma of pregnant women with preeclampsia. Am J Obstet Gynecol 184(3):414-419

14. Zhong XY, Burk MR, Troeger C, Jackson LR, Holzgreve W, Hahn S (2000) Fetal DNA in maternal plasma is elevated in pregnancies with aneuploid fetuses. Prenat Diagn 20(10):795798

15. Gupta AK, Holzgreve W, Huppertz B, Malek A, Schneider H, Hahn S (2004) Detection of fetal DNA and RNA in placentaderived syncytiotrophoblast microparticles generated in vitro. Clin Chem 50(11):2187-2190

16. Pachl J, Duska F, Waldauf P, Fric M, Fanta J, Zdarsky E (2005) Apoptosis as an early event in the development of multiple organ failure? Physiol Res 54(6):697-699

17. Plenchette S, Filomenko R, Logette E, Solier S, Buron N, Cathelin S, Solary E (2004) Analyzing markers of apoptosis in vitro. Methods Mol Biol 281:313-331

18. Lui YY, Chik KW, Chiu RW, Ho CY, Lam CW, Lo YM (2002) Predominant hematopoietic origin of cf-DNA in plasma and serum after gender-mismatched bone marrow transplantation. Clin Chem 48(3):421-427

19. Lee TH, Montalvo L, Chrebtow V, Busch MP (2001) Quantitation of genomic DNA in plasma and serum samples: higher concentrations of genomic DNA found in serum than in plasma. Transfusion 41(2):276-282 